\title{
O santo que vive no sol: Padre Cícero
}

\author{
TOLOVI, Carlos Alberto. Padre Cícero do Juazeiro do Norte: a construção do mito e seu \\ alcance social e religioso."
}

\section{Ênio José da Costa Brito**}

A proposta da tese é ampla, desafiadora, trabalhosa e de perfil interdisciplinar e transdisciplinar. Diz seu autor:

Tomando a figura de Padre Cícero como referência é possível perceber um processo de santificação que coincide com a construção do mito. Porém este santo mitificado tem algo de específico: ele foi construído pela religiosidade popular e ainda hoje pertence a ela. Afinal, o patriarca do Juazeiro do Norte, carinhosamente chamado como "meu padim", é um santo que "vive no sol" pelo fato de ter morrido afastado das Ordens sacerdotais (TOLOVI, 20I5, p. 5).

Algumas ideias, verdadeiros mantras textuais, são trabalhadas longa e minuciosamente nos seis capítulos que estruturam a tese: a relação entre mito, religião e organização social; a influência do mito e da religião nas estruturas de poder e o deslocamento da força míticoreligiosa do "milagre da Hóstia" para o padre. Percorrerei a tese tecendo comentários, observações e destacando tópicos importantes, ciente de que tais pontuações não dão conta da riqueza da pesquisa.

\footnotetext{
"Pontifícia Universidade Católica de São Paulo, Doutorado em Ciências da Religião, São Paulo, 2015.

"* Professor Titular do Programa de Estudos Pós-Graduados em Ciência da Religião da PUC-SP, coordenador do Grupo de Pesquisa "Imaginário Religioso Brasileiro (Veredas)".
}

Recebido em 5 de setembro de 2016 e aprovado para publicação em Io de setembro de 2016 


\section{Os capítulos}

$\mathrm{Na}$ introdução lemos: “o fenômeno do Padre Cícero não pode ser compreendido de forma isolada, como um acontecimento histórico independente das influências sociais, políticas e econômicas" (TOLOVI, 20I5, p.I5). É importante acrescentar “influências religiosas", pois, epistemologicamente falando, a dimensão religiosa encontra-se no mesmo nível que as outras.

No capítulo I, intitulado "Um cenário propício" (TOLOVI, 20I5, p. 24-64), Tolovi parte dos acontecimentos em nível nacional para chegar a uma compreensão matizada e rica do cenário onde se deram fenômenos da maior importância: transformação da hóstia em sangue e transformação de um pequeno vilarejo em um município que influenciou a política regional, estadual e nacional. Situa o leitor ante um fenômeno religioso que desembocou numa forte transformação social e religiosa de um pequeno povoado nordestino.

Ele fala de "gênesis" do movimento religioso. Numa perspectiva pós-colonial - a que o autor se refere em vários momentos -, é melhor dizer "emergência”. Justifico com Stuart Hall (2006): ele nos lembra que a origem é contingente, é e não é, sua retórica exclui elementos que explicam seu ser-e-não ser, sua indeterminação. Sua fala incorre numa ambivalência, fala do passado no presente e na enunciação junta passado e presente.

Ainda temos algumas referências ao livro de Rui Facó, Cangaceiros e fanáticos. Lembro o comentário de Pedro Vasconcellos sobre ele, pioneiro na abordagem de movimentos rurais, não operários, "mostrando o vínculo deles com a luta contra o latifúndio, embora para muitos de seus participantes essa meta fosse inconsciente, já que obscurecida pelo ideal religioso". Mas,

o problema maior [...] surge quando [Facó] passa a considerar a religião na constituição de Belo Monte. Ai seu olhar de marxista "ortodoxo", incapaz de ver na religião algo além do "ópio do povo", se manifesta fortemente, levandoo a desqualificar a brava gente sertaneja cuja resistência admira. A caracterização depreciativa das práticas religiosas dos sertanejos denuncia os preconceitos do autor (VASCONCELLOS, 2015, p. 54-55).

Tolovi oferece uma ótima referência dos "modelos de administração" dos espaços construídos pelo Pe. Mestre Ibiapina. Um texto recente oferece informações significativas 
sobre este tema: Ibiapina tinha preparado o solo por meio das missões populares que incentivavam o protagonismo e o empoderamento dos leigos/beatos/as (CARVALHO, 2008, p.208). Sobre os aldeamentos (TOLOVI, 2015, p. 53) dá uma explicação que pode ser ainda mais explorada, pois, desde o início da época colonial, a missão cristã junto aos nativos se faz principalmente através dos aldeamentos, das reduções: “Converter os indígenas pressupunha reduzi-los do ser e do seu modo de vida e civilizá-los conforme os padrões europeus. Sua humanização era reduzida à medida em que se iam humanizando nos moldes dos colonizadores" (DOMEZI, 20I5, p.I26).

Tolovi enfrenta duas questões ao longo do capítulo: como entender a ambivalência da fé dos romeiros e romeiras, no caso de Pe. Cícero (TOLOVI, 20I5, p.36)? Como apresentar a religiosidade popular na perspectiva de uma "epistemologia do sofrimento" (ESPÍN, 200o)? Ao considerar a oclusão da seca pelos políticos nordestinos, ilumina a questão citando Celso Furtado (p. 34):

A seca é uma coisa terrível. Muita gente morre, outros têm sua vida encurtada pela fome. Nunca se faz um estudo para medir o custo humano real de uma seca. Geralmente, isso é ignorado, ocultado. A classe política nordestina tem um complexo muito grande com respeito a certas coisas, oculta tudo, não gosta que se estude isso. Porque tem consciência de culpa. Sabe que há tanta coisa que podia ter evitado, mas tem medo que tudo também desmorone, que o mundo deles venha abaixo (FURTADO,I988, p. 24)

“As características estruturais do Mito" (TOLOVIA, 20I5, p. 65-IO5) é o título do capítulo II, que deixa transparecer uma conaturalidade do autor com o tema. Assume-se o desafio de entender o mito pela compreensão de sua estrutura e na perspectiva da busca de sentido, buscando: (a) definir as categorias que fundamentam a concepção do mito; (b) decodificar a sua estrutura; (c) aplicar a estrutura à figura do Pe. Cícero.

O perfil do capítulo é bem filosófico, de matriz feuerbachiana, corajoso e afoito em algumas inferências. Uma ideia é básica: Mito não é apenas narrativa, mas esta é uma das bases principais da sua estrutura: ele

não é simplesmente traduzido por uma narrativa, pois ele diz simplesmente como as coisas se deram. Neste sentido, a vida do mito corresponde à latência 
dos desejos e necessidades da coletividade. Portanto, mito não é o narrado, mas, especialmente, o vivido (TOLOVI, 20I5, p.75).

Deparamo-nos com uma afirmação significativa na p. Ioo: "Se a figura do padre Cícero foi mitificada é porque esta foi enquadrada em uma estrutura que já anteriormente estava pronta". O capítulo III mostrará o que corrobora o processo de mitificação.

Ponto alto deste fundamentado capítulo é ter deixado clara a relação entre "necessidade de transcendência" e "necessidade de conservação", presentes no mito. Vejam-se algumas afirmações: "O ser humano através do mito representa o poder de transcendência, de criar e recriar (TOLOVI, 2015, p. 87); "O mito é dependente de uma necessidade de transcendência, que é uma das características humanas essenciais, que por sua vez está ligada aos limites de sua imanência" (Idem, p. I04). Mas também "conserva através da cultura, conserva através dos valores morais, conserva através da repetição - nos ritos; enfim, conserva através da própria estrutura" (Idem, p. IO4). Vale lembrar que tal estrutura, universal, não elimina as peculiaridades culturais e históricas (Idem, p. 95).

Uma das finalidades do capítulo é explicar a íntima relação entre o ser humano, o mito e a religião:

O mito, mais especificamente, depende de uma necessidade de transcendência. E esta necessidade faz parte de uma das características humanas essenciais que, por sua vez, está diretamente ligada aos limites de sua imanência. Imanência e transcendência, corporeidade e consciência, razão e emoção, são binômicos que compõem a dialética da existência humana que será sempre desafiada pela busca de sentido. Sando assim, buscar o conhecimento dos mitos significa a busca da autocompreensão humana (TOLOVI, 20I5, p.IO4).

O capítulo III tem como título "A estrutura do mito em torno da figura de Padre Cícero do Juazeiro do Norte" (TOLOVI, 2015, p. I06-I25) e apresenta as condições para entender Pe. Cícero em seu processo de santificação e mitificação. São duas as questões basilares: porque o "Milagre da Hóstia" foi atribuído ao Padre Cícero e a Beata foi ignorada, esquecida?' E o que

\footnotetext{
${ }^{\text {I }}$ Não temos muitos estudos sobre a beata (ver FORTI, I999).
} 
leva os fiéis a acreditarem em Pe. Cícero e na Beata Maria de Araújo? O próprio autor explica a intencionalidade do capítulo:

[...] desvelar a íntima relação entre mito e religião. Nascem de um mesmo "lugar" (desejo e necessidade da coletividade), precisam de narradores que se utilizam de uma linguagem simbólica, ganha a vida a partir de uma aceitação coletiva, pressupõem a existência e intervenção de um ser sobrenatural (Deus), exigem sacrifício (mesmo que de forma sutil e velada) e possuem a necessidade de rituais para manterem a existência. Por tudo isso é possível compreender o processo de santificação do Padre Cícero pela religiosidade popular, ao mesmo tempo em que se dá a sua mitificação. A diferença mais explicita entre mito e religião está no fato de que o mito não depende de uma institucionalização burocrática e nem de uma racionalização - como teologia, por exemplo. É por isso também que Padre Cícero foi proclamado santo mesmo estando afastado das Ordens Sacerdotais e mesmo sem ser reconhecido pela hierarquia da Igreja Católica (TOLOVI, 20I5, p.I25).

Uma observação: hoje, quando trabalhamos as relações devoção/promessa no âmbito da religiosidade popular, não as temos circunscrito ao do ut des, pois só esta dimensão jurídica não explica a dinâmica nelas presente. $O$ devoto sente-se também acolhido pelo santo. E não deixa de ser impressionante a capacidade da Religiosidade Popular, em geral olhada como algo superficial, de produzir espaços de libertação:

mesmo não propondo revolução política, social ou econômica ela encontra brechas para construir espaços de autonomia dentro das estruturas de poder. E o mais interessante: se utilizando de símbolos religiosos destas estruturas a partir de uma interpretação autônoma e criativa (TOLOVI, 20I5, p. II4).

O capítulo IV intitula-se "A construção do santo mitificado: Padim Ciço" (TOLOVI, 2015, p.126-16I). Tendo em mãos os elementos que explicam a construção do mito, Tolovi realiza um zoom na figura do "Padim Ciço", para compreendê-lo a partir da perspectiva dos romeiros (Idem, p.I26) e responder à questão: o que teria ele feito para se tornar referência de santidade e esperança para os desesperançados? O resultado é uma narrativa ágil na qual cruza elementos políticos, religiosos e populares de forma criativa, confirmando a indissolúvel 
relação entre mito e religião (Idem, p.I59) e a força e o carisma do Pe. Cícero (Idem, p.I62). O fato de ter abordado no capítulo anterior o processo de construção do mito "possibilitou uma percepção mais ampliada a respeito do carisma e da força de liderança do Patriarca junto aos seus romeiros e romeiras" (Idem, p.I62). Penso que exacerba um pouco a preocupação com a autonomia da religiosidade popular, por parte da Igreja hierárquica do Ceará. E ficou devendo para o seu leitor uma foto da "Sala do Santo" (Idem, p.I6I):

No Nordeste e, principalmente em Juazeiro do Norte, a "sala do santo" se encontra presente em quase todos os lares. Um pequeno altar é organizado na sala onde se faz o ritual tradicional da entronização do Coração de Jesus. Um ritual implantado e incentivado por Padre Cícero essa entronização geralmente é feita marcando uma data especial na família. De preferência a data do casamento. Todos os anos, na mesma data, ocorre o ritual denominado como "Renovação". É o momento de renovar e fortalecer a devoção ao Coração de Jesus. Simbolicamente, a presença do Coração de Jesus na família representa uma forma de proteção e presença constante do divino. E neste espaço há um lugar reservado de forma especial para a imagem de Padre Cícero - chamado carinhosamente por "meu padim" (TOLOVI, 20I5, p.I6I).

O leitor, pensando ainda na construção do Mito, fica curioso para saber dele antes do “Milagre da Hóstia” (I889), pois Pe. Cícero já morava em Juazeiro há I6 anos.

"Noção de Política a partir de uma determinada estrutura" (Idem, p.I62-I84) é o título do capítulo V. Sugestivo o mote que tomou como ponto de partida para discutir política, tomado de Ralph dela Cava, um dos mais importantes estudiosos do Pe. Cícero. ${ }^{2}$ Capítulo teórico, que trabalha no sentido de extrapolar/ir além da noção tradicional de política, como fez ao refletir sobre o mito. Eis o resultado deste esforço analítico: "toda ação coletiva, norteada por uma ideologia, que gera uma forma de organização, colocada em uma relação de poder, dentro de uma correlação de forças na perspectiva de uma finalidade última, pode ser definida como política" (TOLOVI, 20I5, p. I83). Munido desta compreensão sente-se apto para compreender a interface entre política e religião, tomando como referência a figura do Pe. Cícero. Ao final pode perguntar: o que salvou Juazeiro da destruição foi a política?

\footnotetext{
${ }^{2}$ O livro de Cava (1976) é um clássico. Ver também o primoroso trabalho de Barbosa (2007).
} 
O principal objetivo do capítulo é "explicitar a fundamentação teórica que possibilitará melhor compreensão da figura do Padre Cícero em meio aos conflitos que o colocaram em destaque no cenário nacional” (Idem, p.I64). Abre um diálogo com Gramsci com relação à ideologia, e apresenta uma de suas definições: "unidade de fé entre uma concepção de mundo e uma norma de conduta adequada a essa concepção” (Idem, p.I7I). A intenção é a de oferecer elementos para uma análise mais densa da "política eclesiástica”, responsável pela negação do milagre e pela condenação do Pe. Cícero. Circunscrevendo a questão afirma: "o poder se constitui como um ato de fé" (Idem, p.I7I) e "é na política que a individualidade se encontra com a universalidade" (Idem, p.I8I). Duas afirmações fortes a serem mais exploradas.

O capítulo VI, “Mito, Religião e Política em torno da figura do Padre Cícero" (Idem, p. I85-220), volta à relação política e religião envolvendo a Igreja hierárquica, o Estado e a religiosidade popular em torno da figura de Pe. Cícero, tendo sempre presente que a relação de poder é o coração da política (Idem, p.207) e olhando o conceito de política na perspectiva da interindividualidade. Procura responder às seguintes questões: (a) O que estaria por trás da decisão do bispo da época (Diocese do Ceará) ao definir a negação do milagre de forma antecipada - mesmo antes do término das investigações propostas por ele mesmo? (b) O que levou o Pe. Cícero a entrar no cenário conflitante da política partidária sendo ele um sacerdote? (c) O que justificaria a condenação do Pe. Cícero por parte da igreja oficial e a santificação do mesmo por parte do povo nordestino? (d) Pelo seu envolvimento com a política partidária e por sua relação de poder, pela grande quantidade de bens materiais e pela sua ascendência junto ao povo, Pe. Cícero poderia ser comparado a um "coronel de batina”?

Entre as inúmeras informações destaco a apresentação do documento de I4/02/1926, que abre a possibilidade do Pe. Cícero retomar as Ordens Sacerdotais se deixasse Juazeiro e entrasse para a vida religiosa (Idem, p. 217).

Duas palavras marcam o texto; a primeira indica uma ação, a segunda uma situação: relação e ambiguidade ou ambivalência. Sob o aspecto analítico procura sempre estabelecer relações entre mito/religião/política e aponta a ambiguidade presente nos fatos que envolveram Pe. Cícero, a beata Maria Araújo e os romeiros, bem como na política civil e eclesiástica. 


\section{Conclusão}

Carlos Alberto Tolovi, ao assumir como objeto de estudo o fenômeno do Pe. Cícero e Juazeiro do Norte, buscando compreender a construção de seu mito através do processo de santificação, com consequências práticas na realidade sociorreligiosa, política e econômica do município, na região do Cariri, no estado do Ceará e no Brasil, tinha consciência do risco que corria. Pesquisar uma figura tão estudada e trazer algo de novo se apresentava como uma tarefa nada fácil. $\mathrm{Na}$ sua análise, acolheu complexos desafios: compreender o mito, além de sua narrativa, isto é, nos seus elementos essenciais, independentemente de sua época e da sua inserção cultural; compreender o mito do "Padim Ciço" a partir da construção do santo, no âmbito do universo da religiosidade popular, tendo os romeiros como protagonistas e compreender a figura do "Patriarca" em meio aos conflitos entre Igreja hierárquica, Estado e a população pobre em luta pela sobrevivência. Admitir a santidade de Cícero significa assumir as narrativas dos beatos/as e todo o processo de empoderamento da religiosidade popular (TOLOVI, 20I5, p.2II). Dados estes passos, pode concluir pela ocorrência de um processo de santificação/mitificação que realçou não só o carisma, mas a liderança do Pe. Cícero.

O autor nos lembra, ainda, ser necessário ter presentes: a contribuição dada a todo o processo de santificação/mitificação do Pe. Cícero pelas narrativas gestadas no âmbito da religiosidade popular; a participação política no âmbito local, regional e nacional da figura ambivalente, que foi "padre, coronel, político, libertador e santo"; e as constantes relações entre política e religião em torno da figura deste padre.

Para Tolovi, os conflitos envolvendo a Igreja hierárquica, a política partidária e a religiosidade popular frente ao fenômeno do milagre ilustram bem a tensão entre religião e política. Ler esta tese é conhecer um pouco mais as entranhas das relações sempre ambíguas entre poder religioso e político. Para o autor, "Padre Cícero não continua vivo apenas no coração dos romeiros e romeiras, mas continua vivo também no campo da política, na latência dos conflitos que ainda permanecem em torno de sua figura dentro e fora da Igreja" (Idem, p. 224). 


\section{Bibliografia}

BARBOSA, Francisco Salatiel de Alencar. O Joaseiro celeste: Tempo e paisagem na devoção ao Padre Cícero. São Paulo: Attar, 2007.

CARVALHO, Ernando Luiz Teixeira. A missão Ibiapina. A crônica do século XIX escrita por colaboradores e amigos do Padre Mestre atualizada com notas e comentários. Passo Fundo: Berthier, 2008.

CAVA, Ralph della. Milagre em Juazeiro. 2 ed. Rio de Janeiro: Paz e Terra,1976.

FACÓ, Rui. Cangaceiros e fanáticos. $3^{\mathrm{a}}$ ed. Rio de Janeiro: Civilização Brasileira, 1972.

DOMEZI, Maria Cecília. Deuses em guerra e pactos na América Latina Colonial. São Paulo: Ideias \& Letras, 2015.

ESPIN, Orlando. A fé do povo. Reflexões teológicas sobre o catolicismo popular. São Paulo: Paulinas, 2000.

FORTI, Maria do Carmo P. Maria Araújo: a beata do milagre. São Paulo: Annablume, 1999.

FURTADO, Celso. Formação econômica do Brasil. São Paulo: Editora Nacional, 1965.

HALL, Stuart. Quando foi o Pós-Colonial? In: SOVIK, Liv (Ed.). Da Diáspora: identidades e mediações culturais. Belo Horizonte: UFMG, 2006.

VASCONCELLOS, Pedro Lima. O Belo Monte de Antonio Conselheiro. Uma invenção "biblada". Maceió: EDUFAL, 2015. 